\title{
Characterization of VC Coatings on Cold Work Tool Steel Produced by TRD
}

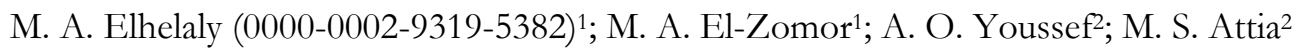 \\ ${ }^{1}$ Heat Treatment Department, Tabbin Institute for Metallurgical Studies, Helwan 109, Cairo 11421, Egypt. Email: \\ melhelaly2018@yahoo.com \\ ${ }^{2}$ Chemistry Department, Faculty of Science, Ain Shams University, Abbassia, Cairo 11566, Egypt
}

In This study vanadium carbide coatings obtained by thermo-reactive deposition/diffusion (TRD) technique on cold work tool steel AISI D3. The TRD treatment were carried out in a molten mixture consisting of $\mathrm{NaCl}, \mathrm{CaCl}_{2}$, ferrovanadium and aluminum, by heating this mixture at $1000{ }^{\circ} \mathrm{C}$ for $4 \mathrm{~h}$ using a resistance-heating furnace under air atmosphere. The coating process was investigated using light microscopy LM, scanning electron microscopy/energy dispersive spectroscopy SEM/EDS, and X-ray diffraction XRD characterization techniques. The results indicated that the vanadizing process produced a homogeneous coating layer about $13 \mu \mathrm{m}$ depth and its microhardness is $2300 \mathrm{HV}$. Carbide compounds that are formed are vanadium carbides phases $\left(\mathrm{VC}, \mathrm{V}_{4} \mathrm{C}_{3}, \mathrm{~V}_{6} \mathrm{C}_{5}, \mathrm{~V}_{2} \mathrm{C}\right)$, while EDS-Line scan results show chromium carbides phases formed in sublayer. In a 3.5 percent $\mathrm{NaCl}$ solution, the corrosion resistance of vanadium carbide coatings was assessed using potentiodynamic polarization and electrochemical impedance spectroscopy (EIS). The corrosion resistance of the substrates was improved by vanadium carbide coatings, vanadium carbide coatings showed the longest service life compared with the uncoated tool steel AISI D3.

Keywords: Thermo-Reactive Diffusion, Vanadium Carbide Coating, Microhardness, Corrosion, Tool Steel

\section{Introduction}

The coating technologies have been applied to improve corrosion, oxidation resistance at room and high temperature and wear resistance without effect on the mechanical properties of the bulk materials [1]. Different techniques to form a surface layer such as plasma spraying [2, 3], Physical Vapor Deposition (PVD) [4, 5], Chemical Vapor Deposition (CVD) [6] and Thermo-Reactive Diffusion (TRD) [7] have been widely used to provide high quality coating on tool and automotive components surfaces [1]. Chemical Vapor Deposition can lead to a heavy distortion of the treated parts, and Physical Vapor Deposition requires complicated and expensive equipment [8]. Industry is most interested in the Thermo-Reactive Diffusion process because of its low cost and flexibility, since it can be used on substrates of various heights and shapes. This method is used in the current project, thermo-reactive diffusion and deposition TRD treatment is a procedure in which a carbide former element is deposited onto the surface of a substrate containing carbon to create carbide layers of that element. TRD is a relatively easy technique and more environmentally friendly compared to other processes [9]. TRD has the advantage that it can deposit homogenous and dense layers that can be applied to steels and alloys containing carbon that has percentages higher than 0.3 wt. $\%$ [10]. TRD is usually used to produce diffusion carbide coatings via one of three methods, pack cementation [11-13], fluidized bed [14-16], or molten salt bath [17-21] method (used in this paper).

In TRD by molten salt bath method, the alloy steels used as the base are immersed in molten salts and carbide forming elements (CFE) such as vanadium, niobium, titanium, chromium, tungsten, or ferroalloys of these elements and their oxides, which are applied in powder form. Carbon atoms diffuse outward from the substrate to the surface, where they react with carbide forming elements to form the carbide coatings [10, 22].

Vanadizing coating is widely used in TRD technique to increase the wear and corrosion resistance of the steel and its alloys, because vanadium carbides phases have a high hardness and good adhesion to the steel substrate [9], its thickness provided by this method is around 2 to $20 \mu \mathrm{m}$ [23].

TRD technique procedures are summarised as immersing a working piece in a fused salt bath for a few hours, ranging from 1 to 8 hours, at temperatures ranging from $800{ }^{\circ} \mathrm{C}-1250{ }^{\circ} \mathrm{C}$ [24-26]. However, the operators can monitor a number of parameters, including the order in which the salt bath components are applied to the crucible, as well as the V concentration at the time the pieces are added.

In this research, the vanadium carbides layer growth behavior and its thickness, microstructure evolution on cold work tool steel AISI D3 by TRD 
technology in chlorides salt bath were analyzed. Besides, the corrosion behavior and microhardness of carbides layer were also tested.

\section{Experimental Procedures}

\subsection{Material and Sample Preparation}

In this study, cold work tool steel AISI D3, was used as coating substrate, with chemical composition is shown in Table 1. Samples were cut to rectangular shape with dimensions: $15 * 10 * 10 \mathrm{~mm}$, before the Tab. 1 Chemical composition of AISI D3 steel (wt. \%).

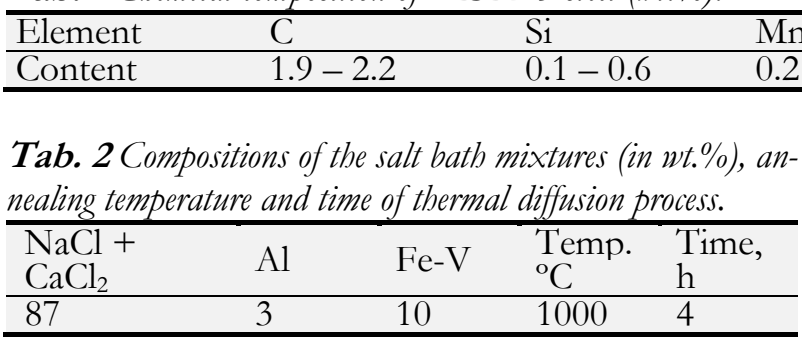

\subsection{Growth of the Coatings}

In an electrical furnace, the following heat treatments were performed. The $\left(\mathrm{NaCl}+\mathrm{CaCl}_{2}\right)$ mixture was first melted in a steel cylindrical crucible, followed by the addition of ferro vanadium powder and aluminium, which was then dissolved. The treatments occurred at $1000^{\circ} \mathrm{C}$ and $4 \mathrm{~h}$. After the TRD treatment, the specimens were removed from the fused bath and quenched in oil; the specimens were then washed in hot water to prepare for characterization.

\subsection{Corrosion Resistance Tests}

In order to evaluate the corrosion resistance of the coated specimens and the uncoated, electrochemical impedance spectroscopy (EIS) and Tafel polarization tests were performed. The polarization and the EIS tests were achieved, in an Voltalab 40 PGZ 301France. These two experiments followed the procedures outlined in ASTM G5 and ASTM G52, respectively [27]. The following conditions were used to establish the Tafel polarization analysis: $1.50 \mathrm{~cm}$ of exposed specimen area in the corrosion medium; distilled water solution with $3.5 \% \mathrm{NaCl}$ at room temperature; initial electric potential (Ei): $-250 \mathrm{mV}$; final electric potential (Ef): $250 \mathrm{mV}$; scan speed of 0.5 $(\mathrm{mV} / \mathrm{sec})$; and initial electric potential (Ei): $-250 \mathrm{mV}$. The EIS experiments were carried out in the same corrosion medium with the following parameters: 100 $\mathrm{kHz}$ initial frequency, $10 \mathrm{MHz}$ final frequency, and 10 $\mathrm{mV}$ AC voltage.

\subsection{Metallographic and Hardness Examinations}

The cross section of specimens was analyzed by light microscope, after being mounted in Bakelite and grounded progressively with silicon carbide papers up to 1200 grit, polished on cloth using 1 and $0.3 \mu \mathrm{m}$ alu- coating process, the surface was ground to 800 grits with abrasive $\mathrm{SiC}$ papers, washed with distilled water, and ultrasonically cleaned with ethanol. The salts mixture, shown in Table 2 used for vanadium carbide coatings consists of aluminum powder with particle size $\leq 125 \mu \mathrm{m}$ as an aluminum source used as reducing agent, ferrovanadium powder $(80 \% \mathrm{~V})$ of particle size $\leq 200 \mu \mathrm{m}$ as a vanadium source used as carbide-forming element, and mix. of halide salts $(\mathrm{NaCl} \mathrm{33 \% -}$ $\mathrm{CaCl}_{2}$ 67\%).

\begin{tabular}{lllll}
\hline In & $\mathrm{P}$ & $\mathrm{S}$ & $\mathrm{Cr}$ & $\mathrm{Fe}$ \\
\hline $2-0.6$ & 0.03 & 0.03 & $11-13$ & Base \\
\hline
\end{tabular}

mina suspensions and etched in nital $2 \%$ solution containing $2 \mathrm{ml} \mathrm{HNO3}+98 \mathrm{ml}$ ethyl alcohol (ASTM E407-07) [28]. The specimens were then observed by SEM/EDS in order to study the structure, morphology and composition of the coatings, X-ray diffraction (XRD) was performed on the specimens using a PANalytical X'pert PRO unit with $\mathrm{Cu} \mathrm{K}$ alpha radiation at $45 \mathrm{kV}$ and $40 \mathrm{~mA}$. This makes the angle of the detector moved from 2Theta $=10$ to 100 degrees.

The microhardness profile of coating/substrate was measured on the cross section with LECO LM70USA -microhardness Vickers HV using $50 \mathrm{~g}$ load with dwell time $10 \mathrm{sec}$. The reported hardness values were the average of at least three measurements.

\section{Results and Discussion}

\subsection{Characterization of the Coatings}

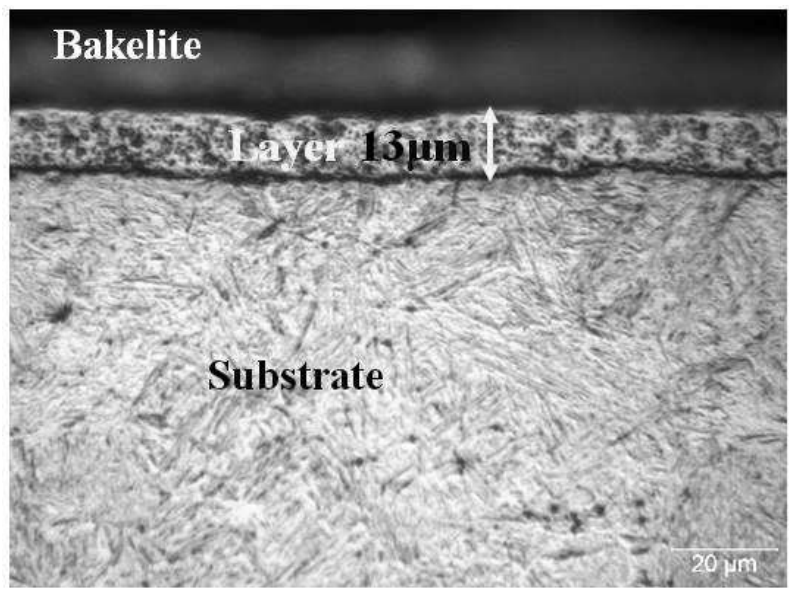

Fig. 1 The cross-sectional $L M$ image of the VC coating at $1000^{\circ} \mathrm{C}$, $4 \mathrm{~h}$ with chemical etching.

The micrographic appearance for AISI D3 cold work tool steel which was vanadized at $1000{ }^{\circ} \mathrm{C}, 4 \mathrm{~h}$ is shown in the light microscope figure 1. It is clear that, formation one layer with total thickness approximately $13 \mu \mathrm{m}$. The vanadized layer and substrate are clearly defined and separated by a planar interface without the presence of a transition zone between the coating and the substrate. The coating exhibits a compact, contin- 
uous, and homogeneous structure with constant thickness and is free of micro-cracks, and good adhesion with substrate as indicated by the absence of chipping segments during cutting before microstructure analysis preparation. On the substrate surface, a layer of supersaturated solid solution is formed, from which nucleation of the carbides begins, growing outwards from the substrate through the reaction between the carbide forming element CFE, the salt bath, and the carbon atoms diffused from the substrate [13, 29 - 31]. The microstructure of the coatings produced with a TRD system depends on the surface mobility of atoms in the substrate surface, which is controlled by the deposition parameters and the chemical properties of the substrate. Depending on the value of the carbon activity on the surface, different morphologies can modify the mechanical performance and corrosion resistance of the coating. The coating can exhibit a microstructure of elongated grains when it grows on a substrate with low values of carbon activity, which allows a decrease in the diffusion of the carbon atoms to the surface. It can also exhibit a microstructure of equiaxed grains when the substrate has sufficient carbon activity to increase the nucleation density, which produces a decrease in the grain size and the formation of a compact microstructure [32].

Vanadium carbide coating specimens were subject to microstructure investigation. The micrographic appearance for AISI D3 tool steel which was vanadized at $1000^{\circ} \mathrm{C}, 4 \mathrm{~h}$ is shown in the scanning electron micrograph figure 2 using "Back Scattering Detector BSD" imaging technique with the EDS major elemental concentration profiles and mapping analysis. It is clear that, one layer of vanadium carbide with total thickness $13 \mu \mathrm{m}$, the distributions of elements indicate that, in top surface of coated specimen $\mathrm{V}$ concentration high increasing to formation vanadium carbide layer then sharp decreasing at the substrate, Fe very low concentration in layer thickness then sharp increasing in substrate, the $\mathrm{C}$ content increasing at the top surface to contact with $\mathrm{V}$ element to formation VC layer, then decreasing in substrate.

The XRD analysis of coating surface, figure 3 indicated the presence of $\mathrm{VC}$ (cubic, $\mathrm{Fm}-3 \mathrm{~m}$ ), $\mathrm{V}_{2} \mathrm{C}$ (orthorhombic, $\mathrm{Pbcn}$ ), $\mathrm{V}_{4} \mathrm{C}_{3}$ (hexagonal, $\mathrm{R}-3 \mathrm{~m}$ ), $\mathrm{V}_{6} \mathrm{C}_{5}$ (hexagonal, $\mathrm{P}_{1}$ ) phases

\subsection{Microhardness of Coating Layer and Substrate}

The Microhardness data, measured by Vickers hardness tester with penetration force $\mathrm{P}=10 \mathrm{gf}$, Dwell time $=10 \mathrm{sec}$, show that:

The effect of vanadium carbide coating at $1000^{\circ} \mathrm{C}$, $4 \mathrm{~h}$ on surface hardness of AISI D 3 tool steel is illustrated in figure 4, generally, the VC layer is a brittle phase, the microhardness of coated layer at $5 \mu \mathrm{m}$ about $\approx 2300 \mathrm{HV} \pm 90$ approximately $400 \%$ increasing in microhardness than martensitic substrate, then gradually decreased from outer surface (VC phases) to the interface between the layer and substrate at $15 \mu \mathrm{m}$ about $\approx 1125 \mathrm{HV} \pm 45$, sharp decrease at substrate about $\approx 660 \mathrm{HV} \pm 5$.
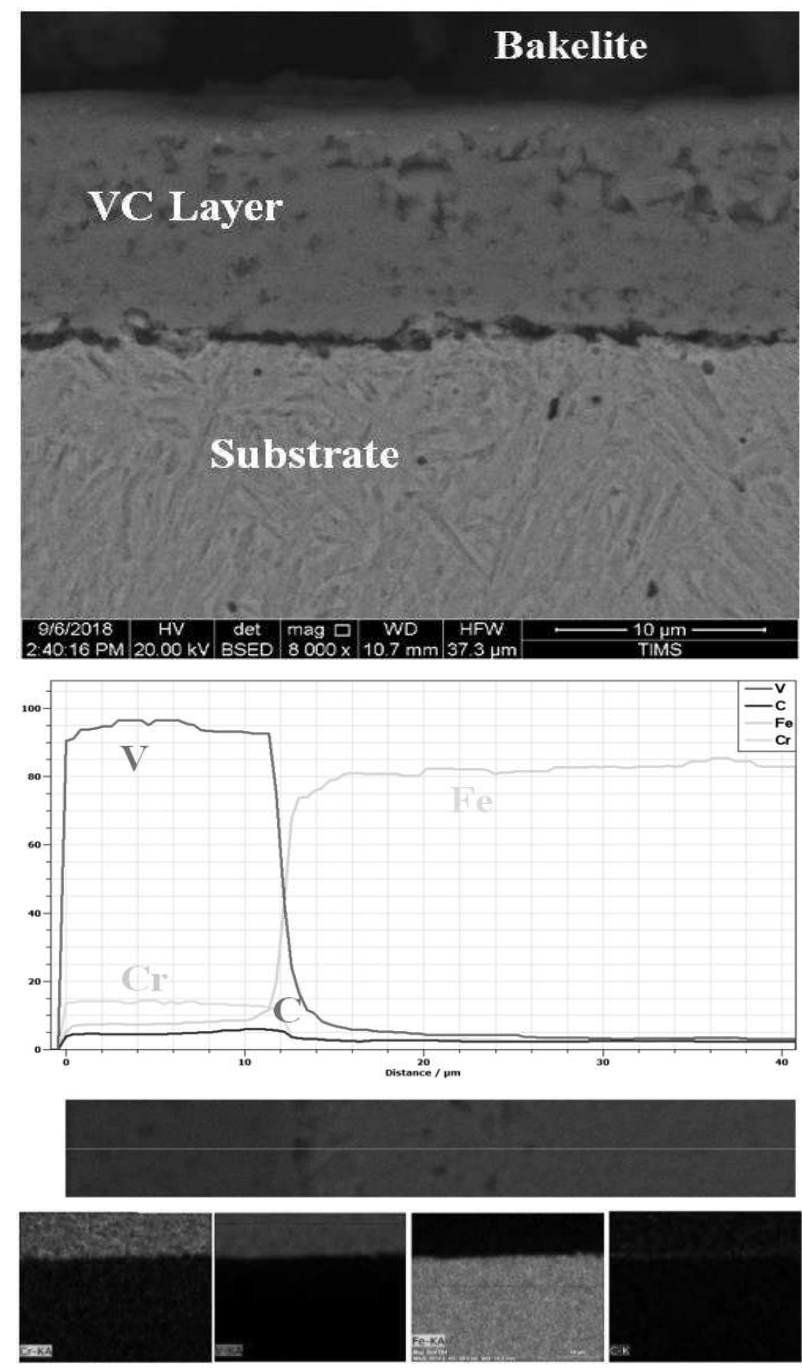

Fig. 2 The cross-sectional SEM image, line-scan and mapping analysis of vanadium carbide coating on AISI D3 at $1000{ }^{\circ} \mathrm{C}$ for $4 \mathrm{~h}$.

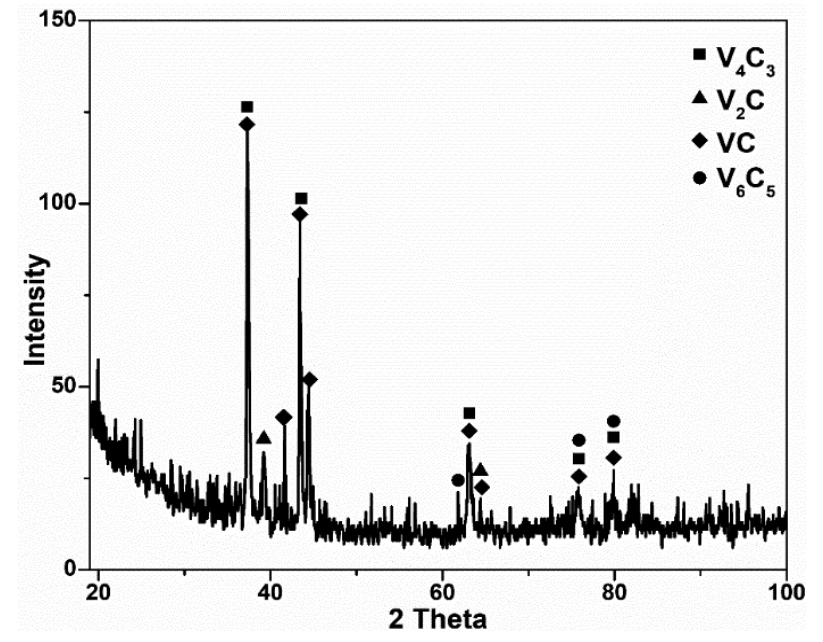

Fig. 3 XRD diffractogram of the surface of $V C$ coating specimen at $1000{ }^{\circ} \mathrm{C}$ for $4 \mathrm{~h}$ identifying $V C, V_{2} C, V_{4} C_{3}$ and $V_{6} C_{5}$ phases. 


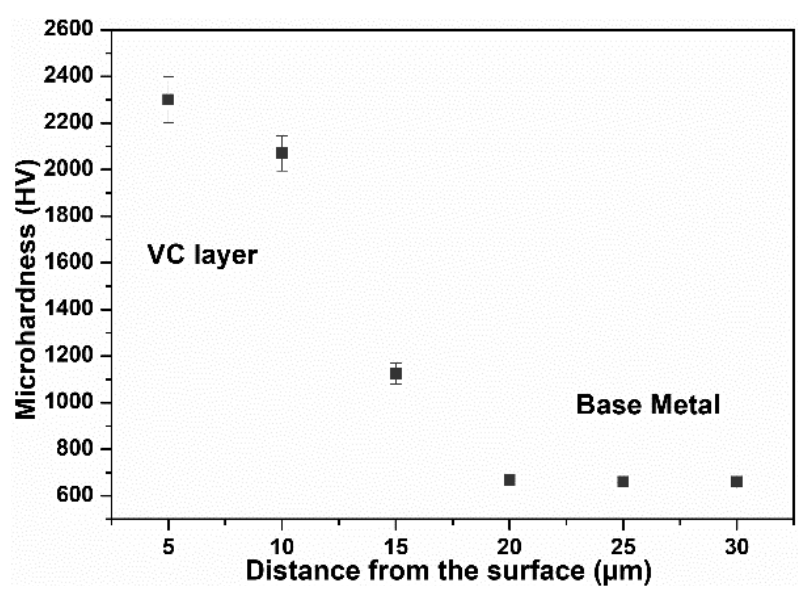

Fig. 4 Variation of the microhardness versus distance from the surface of the specimen coated at $1000{ }^{\circ} \mathrm{C}, 4 \mathrm{~h}$.

\subsection{Corrosion Behavior}

The corrosion behavior was evaluated for the substrate and the coating for comparison (figure 5). The corrosion potential, the corrosion current, and the polarization resistance were evaluated. The results showed that the corrosion potential of the substrate was on average $506 \mathrm{mV}$ and for the coating $370 \mathrm{mV}$, with respect to the reference potential. The corrosion current showed a reduction from $3632 \mathrm{nA}$ to $2220 \mathrm{nA}$, implying a lower flow of ions to the coating. Finally, polarization resistance was consequently lower for the substrate, than for the coating. Within the range of potential evaluated, no pitting or passivation processes were observed for the tests performed. According to Castillejo [33] and Orjuela et al. [34], as was evident from techniques such as XPS formation of vanadium oxides on the surface, these oxides tend to increase the corrosion resistance due to their high chemical stability. Reported failure mechanisms for the coatings are mainly related to the porosity. These defects allow the passage of electrolyte from the surface to the interface, thus exposing the substrate to electrochemical etching [32].

Corrosion parameters obtained in this investigation for the case of Ecorr are $-370 \mathrm{mV}$ less negative than those reported by Orjuela [34] for vanadium carbide deposited on AISI H13 steel $(-655 \mathrm{mV})$ and AISI D2 steel $(-605 \mathrm{mV})$.

The results obtained by means of EIS show that the uncoated D3 steel presents the highest peaks with respect to the phase angle, which is interpreted as the ability to create a passivation layer, in this case, possibly oxide of chromium and oxides of iron, mainly because of the high chromium content in this type of steel. However, this passivating layer does not seem to be very strong, because at low frequencies the phase angle (below $20^{\circ}$ ) and the impedance value are markedly reduced. In the D3 steel coated with vanadium carbide, a shift of the curves towards lower frequency values is observed (figure 6), which shows that the coating improves the resistance to corrosion of the system to a certain extent.

The layer is very stable and chemically resistant to aggressive agents $(\mathrm{NaOH}, \mathrm{HCL}, . .$.$) [35]. Strong met-$ allurgical compound between the carbide layer and the basic material (steel substrate) gives good attenuation of the surface layer for the base material [35].

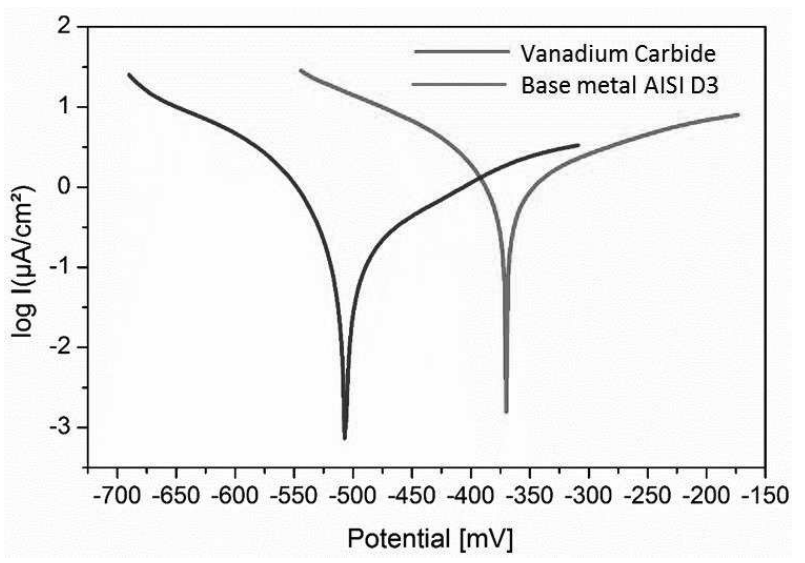

Fig. 5 Potentiodynamic polarization curves for coated and uncoated D3 steel, measured in a 3.5\% NaCl test solution.

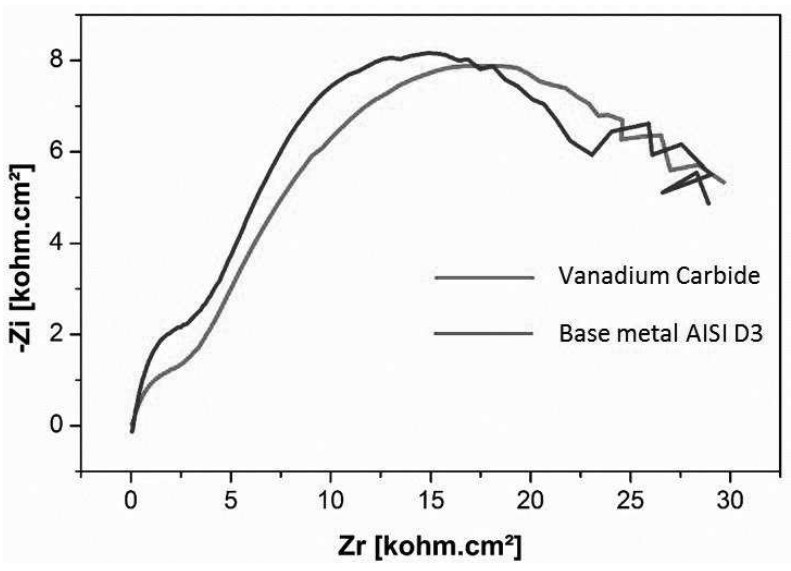

Fig. 6 Nyquist diagrams obtained via EIS on coated and uncoated D3 steel, measured in a 3.5\% NaCl test solution at $23 \pm 2{ }^{\circ} \mathrm{C}$.

\section{Conclusions}

Hard coatings of vanadium carbide can be produced via the Thermo-reactive diffusion TRD technique on AISI D3 steel. The TRD process produces coatings with a defined, continuous, dense, and homogenous interface at temperatures $1000^{\circ} \mathrm{C}$ after $4 \mathrm{~h}$ of treatment with layer thicknesses equal 13 microns and its microhardness of this layer was $2300 \mathrm{HV}$ closed to VC phases. Carbide compounds that are formed are vanadium carbides phases $\left(\mathrm{VC}, \mathrm{V}_{4} \mathrm{C}_{3}\right.$, $\mathrm{V}_{6} \mathrm{C}_{5}, \mathrm{~V}_{2} \mathrm{C}$ ) and chromium carbides phases.

Hard coatings of vanadium carbide deposited on D3 tool steel exhibit better electrochemical behavior than the substrate, shown in the higher values of corrosion potential and lower values of interchange cur- 
rent for the coating, the results showed that the corrosion potential of the substrate was an average -506 $\mathrm{mV}$ and for the coating $-370 \mathrm{mV}$, due to its ceramic composition and chemical stability, and can be used as a protective layer on steel used for fabricating cutting tools.

\section{References}

[1] AGHAIE-KHAFRI, M., AND F. FAZLALIPOUR. (2008). "Vanadium carbide coatings on die steel deposited by the thermoreactive diffusion technique." Journal of Physics and Chemistry of Solids 69.10: 2465-2470.

[2] CUI, Y. H., HU, Z. C., MA, Y. D., YANG, Y., ZHAO, C. C., RAN, Y. T., ... \& YAN, D. R. (2019). Porous nanostructured $\mathrm{ZrO} 2$ coatings prepared by plasma spraying. Surface and Coatings Technology, 363, 112-119.

[3] KRBAŤA, M., MAJERÍK, J., BARÉNYI, I., MIKUŠOVÁ, I., \& KUSMIČ, D. (2019). Mechanical and tribological features of the $90 \mathrm{MnCrV} 8$ steel after plasma nitriding. Manufacturing Technology, 19, 238-242.

[4] QADIR, M., LI, Y., \& WEN, C. (2019). Ionsubstituted calcium phosphate coatings by physical vapor deposition magnetron sputtering for biomedical applications: A review. Acta biomaterialia, 89, 14-32.

[5] KALINCOVÁ, D., ŤAVODOVÁ, M., \& JAKUBÉCZYOVÁ, D. (2018). Quality evaluation of the coatings and its influence on the wood machining tool wear. Manufacturing Technology, 18(4), 578-584.

[6] RAUCHENWALD, E., LESSIAK, M., WEISSENBACHER, R., \& HAUBNER, R. (2019). Chemical vapor deposition of $\mathrm{ZrN}$ using in situ produced $\mathrm{ZrCl} 4$ as a precursor. $\mathrm{Ce}$ ramics International, 45(7), 9410-9414.

[7] ZHANG, J., LI, S., LU, C., SUN, C., PU, S., XUE, Q., ... \& HUANG, M. (2019). Anti-wear titanium carbide coating on low-carbon steel by thermo-reactive diffusion. Surface and Coatings Technology, 364, 265-272.

[8] MATIJEVIĆ, B. (2013). A model of vanadium carbide growth on steel surfaces obtained by thermo reactive deposition. Jom, 65(11), 13951402.

[9] GHADI, A., SOLTANIEH, M., SAGHAFIAN, H., \& YANG, Z. G. (2016). Investigation of chromium and vanadium carbide composite coatings on CK45 steel by Thermal Reactive Diffusion. Surface and Coatings techno$\log y, 289,1-10$.
[10] ARAI, T., \& HARPER, S. (1991). Thermoreactive deposition/diffusion process. ASM International, ASM Handbook., 4, 448-453.

[11] KURT, BÜLENT, YILMAZ KÜÇÜK, AND M. SABRI GÖK. (2014). "Microabrasion wear behavior of $\mathrm{VC}$ and $\mathrm{CrC}$ coatings deposited by thermoreactive diffusion technique." Tribology Transactions 57.2: 345-352.

[12] ELHELALY, M. A., ELZOMOR, M. A., AHMED, M. H., \& YOUSSEF, A. O. (2019). Effect of Zirconium Addition on High-Temperature Cyclic Oxidation of Diffusion ChromoAluminized Ni-Base Superalloy. Oxidation of Metals, 91(1), 159-175.

[13]

[14] ELHELALY, M.A., EL-ZOMOR, M.A., ATTIA, M.S. AND YOUSSEF, A.O., 2021. Characterization and Kinetics of Chromium Carbide Coatings on AISI O2 Tool Steel Performed by Pack Cementation. Journal of Materials Engineering and Performance, pp.1-11.

[15] WEI, C. Y., \& CHEN, F. S. (2005). Thermoreactive deposition/diffusion coating of chromium carbide by contact-free method. Materials Chemistry and physics, 91(1), 192-199.

[16] CHEN, F. S., LEE, P. Y., \& YEH, M. C. (1998). Thermal reactive deposition coating of chromium carbide on die steel in a fluidized bed furnace. Materials chemistry and physics, 53(1), 1927.

[17] KING, P. C., BROWNRIGG, A., LONG, J. M., \& REYNOLDSON, R. W. (2004). Fluidized bed $\mathrm{CrN}$ coating formation on prenitrocarburized plain carbon steel. Journal of materials engineering and performance, 13(4), 431-438.

[18] FAN, X. S., YANG, Z. G., ZHANG, C., ZHANG, Y. D., \& CHE, H. Q. (2010). Evaluation of vanadium carbide coatings on AISI H13 obtained by thermo-reactive deposition/diffusion technique. Surface and Coatings Tecbnology, 205(2), 641-646.

[19] KARIMI ZARCHI, H. R., JALALY, M., SOLTANIEH, M., \& MEHRJOO, H. (2009). Comparison of the activation energies of the formation of chromium carbide coating on carburized and uncarburized AISI 1020 steel. steel research international, 80(11), 859-864.

[20] GHADI, A. A., \& SOLTANIEH, M. (2015). Effect of carbon presence in the substrate and salt bath on the formation of chromium coating layers on steel through TRD process. J. Ceram. Process. Res, 16, 657. 
[21] GHADI, A., SOLTANIEH, M., \& KARIMI ZARCHI, H. R. (2012). Effect of salt bath composition on the chromium diffusion on plain carbon steels by TRD process. In Defect and Diffusion Forum (Vol. 326, pp. 377-382). Trans Tech Publications Ltd.

[22] GHORBANIAN, B., \& KHOIE, S. M. M. (2016). Formation of vanadium carbide with the plasma electrolytic saturation method (PES) and comparison with Thermo Reactive diffusion method (TRD). Acta Metallurgica Slovaca, 22(2), 111-119.

[23] ARAI, T. (1979). Carbide coating process by use of molten borax bath in Japan. Journal of Heat Treating, 1(2), 15-22.

[24] LI, S. N., CHEN, H., ZHANG, Y. J., GAO, Z. Y., LIU, L. Z., MA, B., \& YU, L. N. (2014). A study on effect of beginning $\mathrm{V}$ concentration in TD process. In Applied Mechanics and Materials (Vol. 624, pp. 134-137). Trans Tech Publications Ltd.

[25] XIAOKE, T., RISHENG, P., \& JIE, L. (2000). Effect of rare earth elements on kinetics of salt bath vanadizing [J]. Journal of the Chinese Rare Earth Society (in Chin.), 18(4), 352.

[26] ZHANG, J. (1995). The Rapid Ion Nitrogenizing in the Deep Layer and the Ion S- N- C Composite Permeation, Master Thesis of Xi'an Jiaotong University.

[27] YINCHUN, H., \& YOSKIO, O. S. T. T. I. (1986). Growth of Vanadium Carbide Crystal with A Single Phase and Homogeneous Composition [J]. Journal of the Chinese Ceramic Society, 14(4), 466-472.

[28] ASTM International, ASTM Standard G52, (2011), Standard Practice for Exposing and
Evaluating Metals and Alloys in Surface Seawater.

[29] E04 Committee. (2007). Practice for Microetching Metals and Alloys. ASTM International E407-07.

[30] ARAI, T., FUjITA, H., SUGIMOTO, Y., \& OHTA, Y. (1987). Diffusion carbide coatings formed in molten borax systems. Journal of materials engineering, 9(2), 183-189.

[31] AGHAIE-KHAFRI, M., \& FAZLALIPOUR, F. (2008). Kinetics of V (N, C) coating produced by a duplex surface treatment. Surface and coatings technology, 202(17), 4107-4113.

[32] SHAN, Z. J., PANG, Z. G., LUO, F. Q., \& WEI, F. D. (2012). Kinetics of V (N, C) and Nb $(\mathrm{N}, \mathrm{C})$ coatings produced by $\mathrm{V}-\mathrm{Nb}-\mathrm{RE}$ deposition technique. Surface and Coatings Technology, 206(19-20), 4322-4327.

[33] FAN, X. S., YANG, Z. G., XIA, Z. X., ZHANG, C., \& CHE, H. Q. (2010). The microstructure evolution of $\mathrm{VC}$ coatings on AISI H13 and 9Cr18 steel by thermo-reactive deposition process. Journal of Alloys and Compounds, 505(1), L15-L18.

[34] CASTILLEJO NIETO, F. E. (2013). Recubrimientos de carburos ternarios depositados con la técnica TRD. Facultad de Minas.

[35] ORJUELA GUERRERO, F. A. (2013). Resistencia a la corrosión en recubrimientos de carburo de vanadio y carburo de niobio depositados con la técnica TRD. Facultad de Ingeniería.

[36] STOJANOVIĆ, Ž., STANISAVLJEV, S., \& RADOSAVLJEVIĆ, S. (2013). Application process of vanadizing in the function of extension working life of parts. Zaštita materijala, 54(2), 183-188. 